\title{
Adaptive notch filter under indirect and direct current controls for active power filter
}

\author{
Syahrul Hisham Mohamad', Mohd Amran Mohd Radzi², Nashiren Farzilah Mailah, \\ Noor Izzri Abd. Wahab ${ }^{4}$, Auzani Jidin ${ }^{5}$, Musa Yusup Lada ${ }^{6}$ \\ 1,2,3,4,6 Advance Lightning, Power and Energy Research (ALPER), Faculty of Engineering, \\ Universiti Putra Malaysia, Malaysia \\ ${ }^{1,5,6}$ Faculty of Electrical and Electronic Engineering Technology, Universiti Teknikal Malaysia Melaka, Malaysia
}

\section{Article Info}

Article history:

Received Dec 29, 2019

Revised Mar 7, 2020

Accepted Apr 9, 2020

\section{Keywords:}

Active power filter

Adaptive notch filter

Direct current control

Indirect current control

Total harmonics distortion

\begin{abstract}
This study presents the implementation of adaptive notch filter (ANF) as reference signal extraction for shunt active power filter (APF) in indirect current control (ICC) and direct current control (DCC) modes for three phase system. The ANF functions to filter the signal that inputted to it by producing a fundamental signal and harmonics signal. The advantage of applying the ANF algorithm is based on its simple design that giving the ANF advantages to be utilize in microcontroller. The performance of the ANF is validated though MATLAB simulation in ICC dan DCC configurations. Based on the simulation results, the ANF is capable to work efficiently for both ICC and DCC modes, but in term of efficiency, the ICC mode is clearly showing a better harmonics mitigation result. Base on the result also it shown that the ANF is capable of mitigate the harmonics below the standard required by the IEEE 519-92. The application of ANF is useful to be applied due to its simple design and filtering method.
\end{abstract}

This is an open access article under the CC BY-SA license.

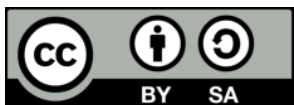

\section{Corresponding Author:}

Syahrul Hisham Mohamad,

Faculty of Electrical and Electronic Engineering Technology,

Universiti Teknikal Malaysia Melaka,

Hang Tuah Jaya, 76100 Durian Tunggal, Melaka, Malaysia.

Email: syahrulhisham@utem.edu.my

\section{INTRODUCTION}

The needs of power quality compensation in electrical power system is becoming more and more crucial nowadays as the increase of the development in power electronics equipment. The trends of power electronic applications are soaring whether within industrial applications or throughout domestic applications. This abundancy leads to the pollution of the electrical power system, which is mostly harmonics [1]. Mitigation or suppressing the harmonics has been suggested within these recent years as the research works in active power filter (APF) have been progressing. This paper specifies on the strategy of extracting the harmonics in order to support the control of the APF.

In developing an APF, one of most important components is the harmonics extraction algorithm. This algorithm functions as the core component in supplying the reference signal to the APF for producing compensative power to the electrical power system. In developing the extraction algorithm, many methods have been studied and applied whether in time or frequency based domains. In frequency based domain, the techniques used are ranging from fast Fourier and discrete Fourier series [2-5], Kalman filtering [6-8] and wavelet transformation [9]. However, working in the frequency domain is a little tedious as it involves transformation of information into frequency domain. The commonly used extraction techniques for the APF 
is within the time domain as it will involve the algorithm to work in real time condition. The time domain is divided into classical methods such as PQ and PQR theory [10-13], synchronous reference frame theory [14-16], and capacitor voltage control techniques. Alternatively, the intelligent techniques have been considered such as neutral network [17], adaptive neural network and adaptive linear neuron [18-21]. Besides the three groups of techniques used widely, another emerging technique is the filtering technique such as adaptive notch filter (ANF), in which this technique has simple design and does not require training.

This paper proposes application of ANF based on the IIR filter as an extraction method of harmonics for indirect current control (ICC) and direct current control (DCC) of APF. By applying the ANF, the filter is capable of tracking the frequency and phase of the system without additional component such as phase lock loop (PLL). Another advantage of applying the ANF is its capability to filter out the fundamental component and selective components of harmonics of the electrical power system.

\section{PRINCIPLE OF ADAPTIVE NOTCH FILTER}

An ideal notch filter is a filter that allows a linear gain at every frequency except at a specified frequency where the gain is zero. Based on this condition, the notch filter is able to withdraw the solicit signal of sinusoidal components from electrical power system within the given frequency.

\subsection{Adaptive notch filter design}

Initially, ANF is designed based on the IIR filter but operating within the frequency domain. However, later on the ANF is transposed into the time domain in order to suite within the time based operation [22]. For better dynamic condition, the ANF is then modified in scalar condition with adaptation mechanism. The dynamic behavior of ANF can be proposed as the following set of differential equations $[23,24]$.

$$
\begin{aligned}
& \ddot{x}+\theta^{2} x=2 \varepsilon \theta e(t) \\
& \dot{\theta}=-y x \theta e(t) \\
& \theta(t)=u(t)-\dot{x}
\end{aligned}
$$

From the set of equation, the system can be explained as following condition. The input signal of the system is given as $\mathrm{u}(\mathrm{t}), \theta$ represents the estimation frequency of the system while $\varepsilon$ and $\gamma$ represent two coefficients that play important role in determining the accuracy and the convergence speed of the system. The two coefficients are randomly set but both values need to compensate each other or otherwise the ANF will not function at its maximum filtering capacity [25]. In a functional single sinusoidal input $\mathrm{u}(\mathrm{t})=\mathrm{A}_{1} \sin \left(\omega_{0} \mathrm{t}+\varphi_{1}\right)$, the used ANF has an explicit characteristic where it is having a unique periodic orbit located at $O$.

$$
O=\left(\begin{array}{c}
\bar{x} \\
\bar{x} \\
\bar{\theta}
\end{array}\right)=\left(\begin{array}{c}
\frac{-A_{1} \cos \left(\omega_{0} t+\varphi_{1}\right)}{\omega_{0}} \\
A_{1} \sin \omega_{0}\left(\omega_{0} t+\varphi_{1}\right) \\
\omega_{0}
\end{array}\right)
$$

Based on the output of the ANF, the filter will produce the cos component of the filtered signal noted by $\mathrm{x}$ but with negative magnitude and sin component is noted by $\dot{x}$ but the value of the sin needs to be scalar with $\omega_{0}$ in order to get right value of filtered input $[26,27]$. The basic structure of the ANF for single-phase system is shown in Figure 1.

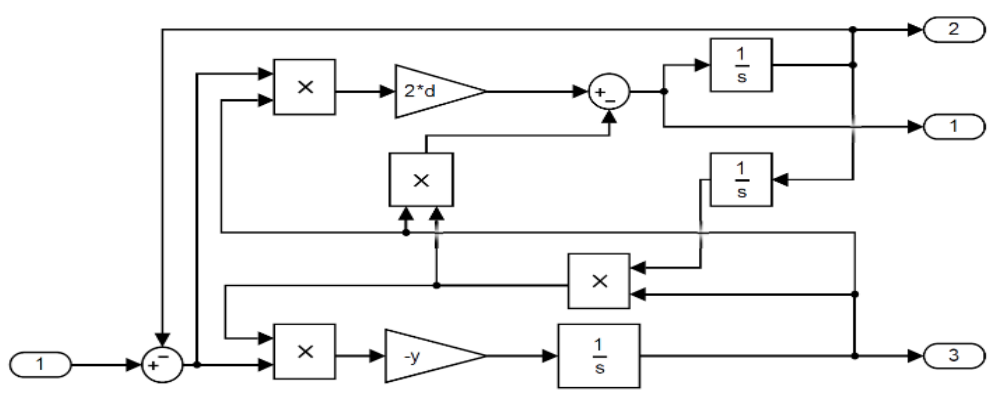

Figure 1. ANF structure for single-phase system 


\subsection{Three-phase ANF}

As shown in the previous section, a singular set of ANF works only for a singular input signal. In order to design a functional three-phase ANF, the arrangement can be generalized to a sequence of three ANFs which will be working in parallel to extract the fundamental components of each of the input signals. Since the structure of the three-phase ANF is having the same frequency over time, the frequency estimator of the system can be shared between them, thus reducing the integration function of the three-phase system [28]. This approach therefore provides decrease in error over preceding method as the ANF is sharing the frequency estimator. Basically, the ANF for three-phase usage is defined by following equations.

$$
\begin{aligned}
& \bar{x}_{n}+\theta^{2} x_{n}=2 \varepsilon \theta e_{n}(t) \\
& \theta=-y \theta \sum x_{n} e_{n}(t) \\
& e_{n}(t)=u_{n}(t)-\dot{x}_{n}
\end{aligned}
$$

where $\mathrm{n}$ is the phase ( $\mathrm{a}, \mathrm{b}$ and $\mathrm{c}$ ) and the update law on the frequency is summation of the error and the signal of all three phases.

The design of the three-phase ANF is shown in Figure 2. It is shown that the ANF structure is divided into two, in which the first structure is the generalized frequency extractor where it is composed from (5) and the second structure is the component extraction [29]. It can be seen that the ANF works by updating the error law in (6) of each individual phase of signal.

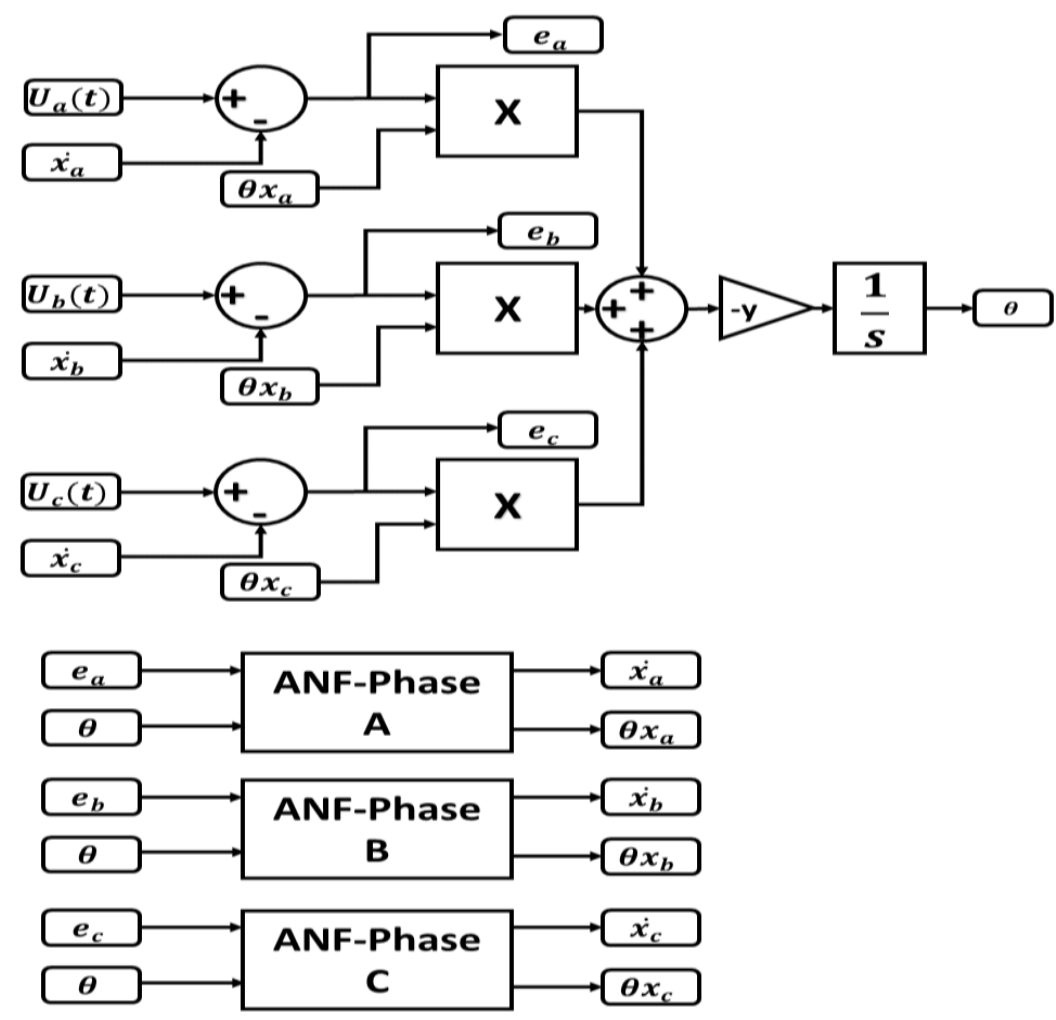

Figure 2. ANF structure for three-phase system

\section{CURRENT CONTROL METHOD OF ANF}

The proposed ANF is designed and simulated in a three-phase shunt APF. The configuration of three-phase shunt APF with ANF as the harmonics extraction is shown in Figure 3. The system is consisting of a three-phase power supply, shunt APF and nonlinear load. The source of harmonics is deviated from the nonlinear load where it consists of three-phase rectifier circuit and attached with an inductive load. For the shunt APF, control strategies are made of harmonics extraction algorithm, current control algorithm and switching algorithm. In this paper, the main extraction algorithm is the ANF where the highlighted item is on the implementation of ANF ICC and DCC modes. The switching algorithm 
is implemented with hysteresis switching control. As shown in Figure 3, the source current is summation of the load current and the harmonics current as in (7).

$$
I_{g}=I_{L}+I_{H}
$$

The reference current signal of the shunt APF can be taken from two mentioned current control methods. For the ICC, the ANF will produce the filtered fundamental input current signal and the signal then will be compared with the supply input current. The difference between both signals will be taken as the input for the shunt APF but with inverse magnitude. This condition is given as follow.

$$
I_{\text {comp }}=I_{\text {load }}-I_{\text {fund }}
$$

Meanwhile, for the DCC, the harmonics signal generated by the ANF is compared to the filter current that are produced by the shunt APF. The harmonics needed for this control is taken from the error value of the ANF as given in (6). The current control is given as (9). The signal given to the shunt APF is the additional value required for filter to reach compensation error between the harmonics signal of the ANF and filtering current.

$$
I_{\text {Comp }}=I_{\text {H+ANF }}-I_{\text {H+SAPF }}
$$

\section{SIMULATION RESULT AND ANALYSIS}

The capabilities of the proposed extraction algorithm is tested and validated by a simulation tool. The simulation is done using MATLAB Simulink with sim power system toolbox. Figures 3 and 4 show the simulation diagram of APF with the ANF for both DCC and ICC modes. The simulation parameters considered are shown in Table 1. In order to obtain the appropriate response of the system, the simulation is done within this order, initially the load is turned off and when the time reaches $0.1 \mathrm{~s}$, the load is truned on, and when the time reaches $0.3 \mathrm{~s}$, the APF is connected to the point of common coupling (PCC).

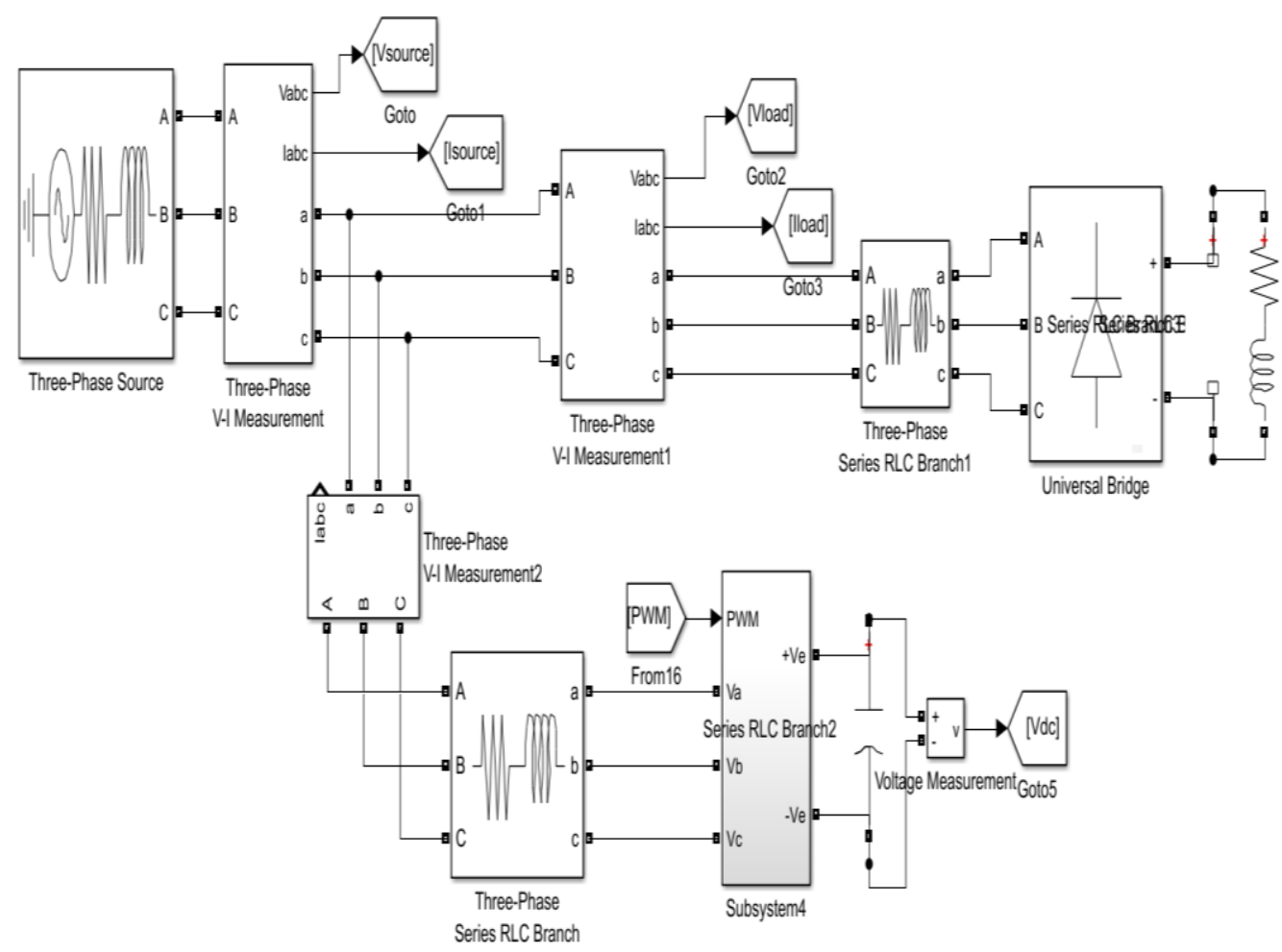

Figure 3. Shunt APF for three-phase system 


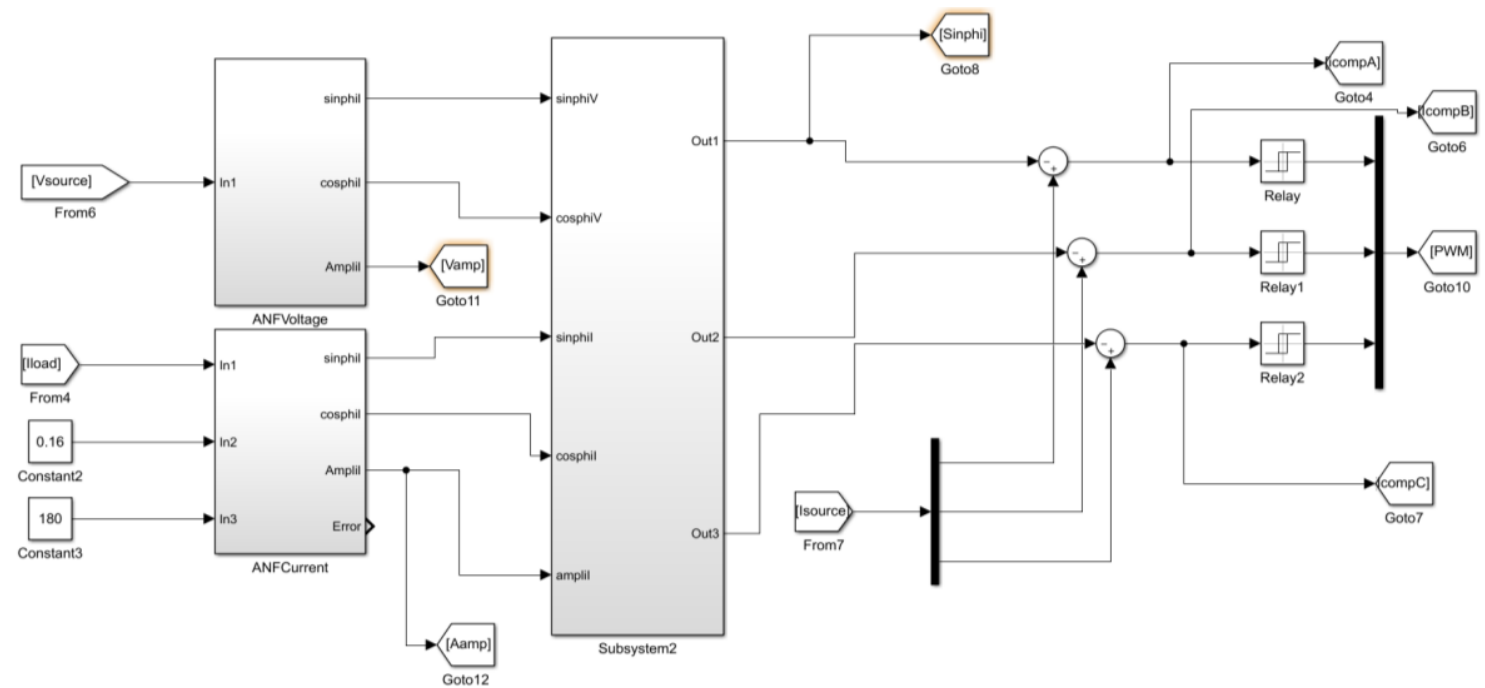

Figure 4. ANF structure in MATLAB Simulink

Table 1. Simulation parameters

\begin{tabular}{lc}
\hline \multicolumn{1}{c}{ Parameter } & Value \\
\hline Source Voltage & $415 \mathrm{~V}(\mathrm{RMS}), 50 \mathrm{~Hz}$ \\
Source Impedance & $1 \Omega, 1 \mathrm{mH}$ \\
Single Phase Nonlinear Load & $60 \Omega, 50 \mathrm{mH}$ \\
DC Link Capacitance and Vref & $3300 \mu \mathrm{F}, 700 \mathrm{~V}$ \\
Filtering Inductor & $5 \mathrm{mH}$ \\
ANF Gains & $\varepsilon=0.16, \mathrm{y}=180$ \\
\hline
\end{tabular}

\subsection{Indirect current control}

The first simulation is done in order to demonstrate performance of the ANF for ICC. Figure 5 (a) shows the source voltage and load voltage within all the simulation stages. As shown in the figure, the source and load voltage waveforms are maintained during all of stages without being affected by the turning of load and APF. Figure 5 (b) shows the source current and load current for the APF with ICC mode. From the figure, the system starts to operate the load at $0.1 \mathrm{~s}$, at this point the source and load currents are having non-ideal sinusoidal waveforms. However, when the APF is applied to the system at 0.2s, the harmonics are managed to be compensated where the current source managed to regain the sinusoidal waveform. The detailed waveforms of source voltage, source current and filter current at the PCC is shown in Figure 6. The figure clearly shows that the source is successfully mitigated by the APF and waveform of the compensation current at the filtering inductor.
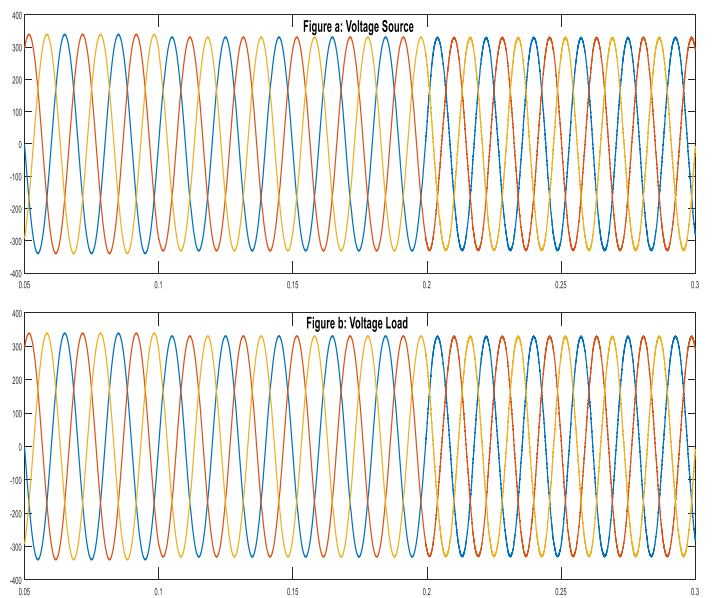

(a)
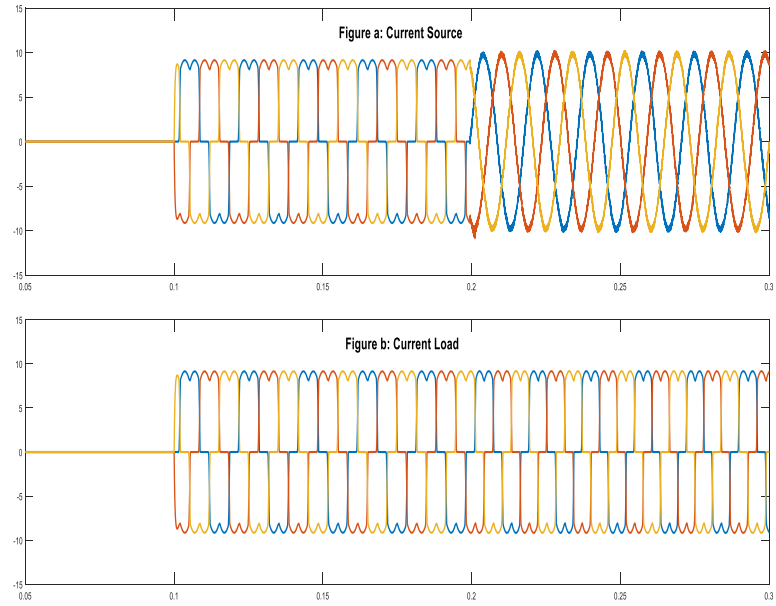

(b)

Figure 5. (a) Source voltage and load voltage for ICC, (b) Source current and load current for ICC 

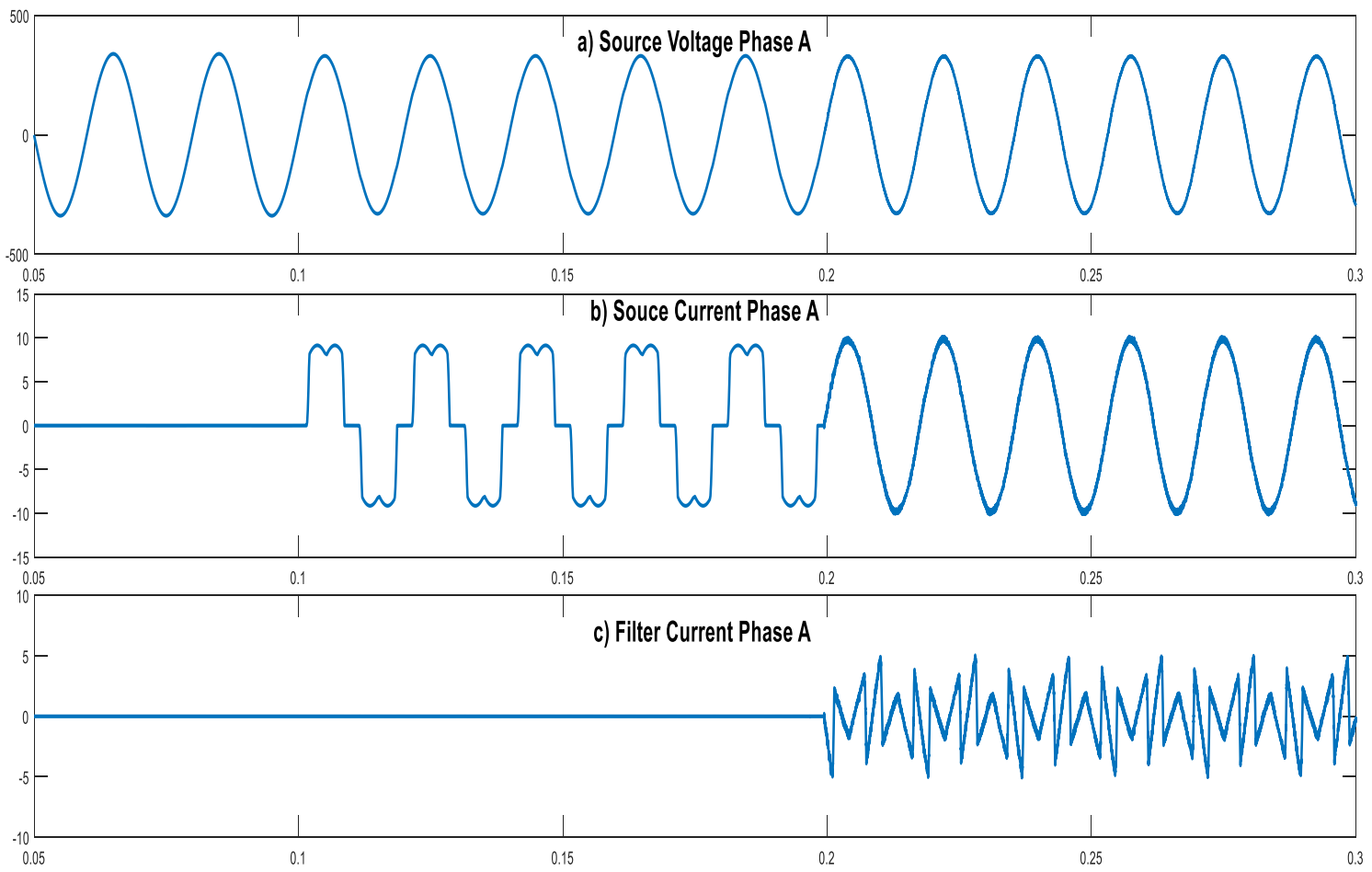

Figure 6. Phase A ICC waveform, (a) Source voltage, (b) Source current and (c) Filter current

\subsection{Direct current control}

The second simulation is done for the ANF using DCC method with the same system specification. As same as the predecessor method, the source and load voltages are maintained during the system is introduced to load and APF as shown in Figure 7 (a). Comparable with ICC method, the DCC method also manages to mitigate the source current when it is applied to the system, and the undesirable sinusoidal waveform that affecting the source current contributed by the load is managed to regain the desire sinusoidal shape. This shows that the APF functions accordingly in reducing the harmonics within the system. As shown in Figure 7 (b), at point $0.2 \mathrm{~s}$, the source current from each phase changes the shape into a sinusoidal waveform. In Figure 8, the detailed waveform of the DCC for phase A is shown. The figure show the source voltage, the source current and the filter current. When the APF is activated at point $0.2 \mathrm{~s}$ and upon operation, it manages to mitigate the harmonics.

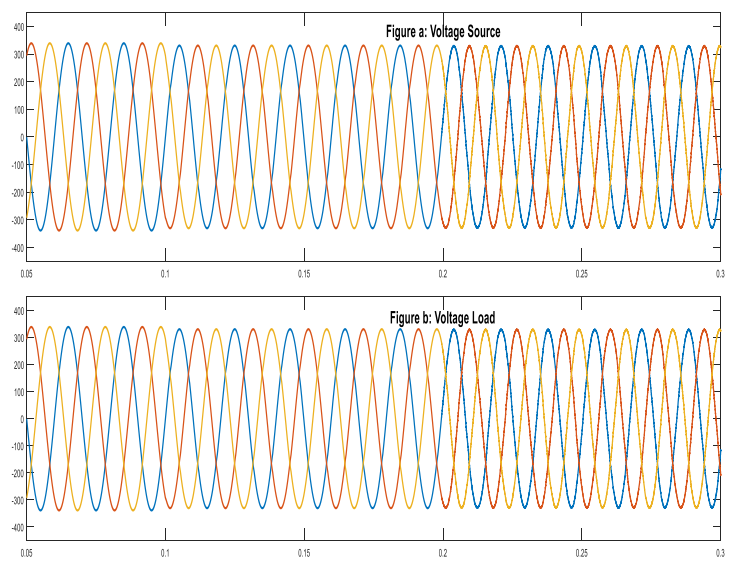

(a)

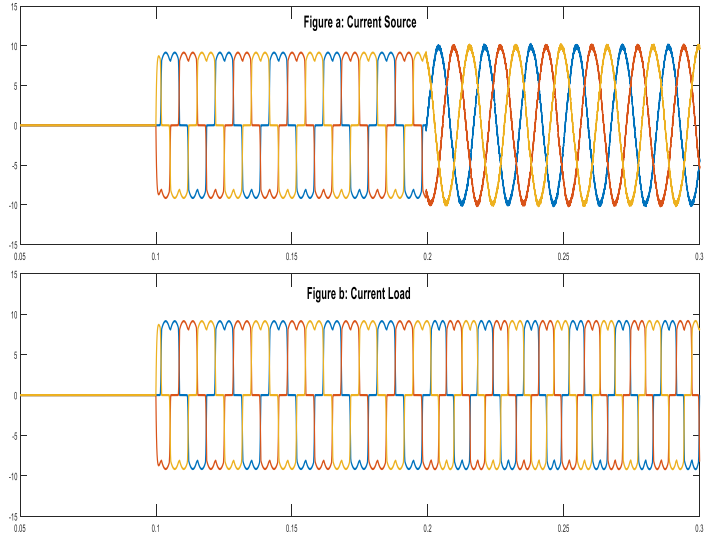

(b)

Figure 7. (a) Source voltage and load voltage for DCC, (b) Source current and load current for DCC 

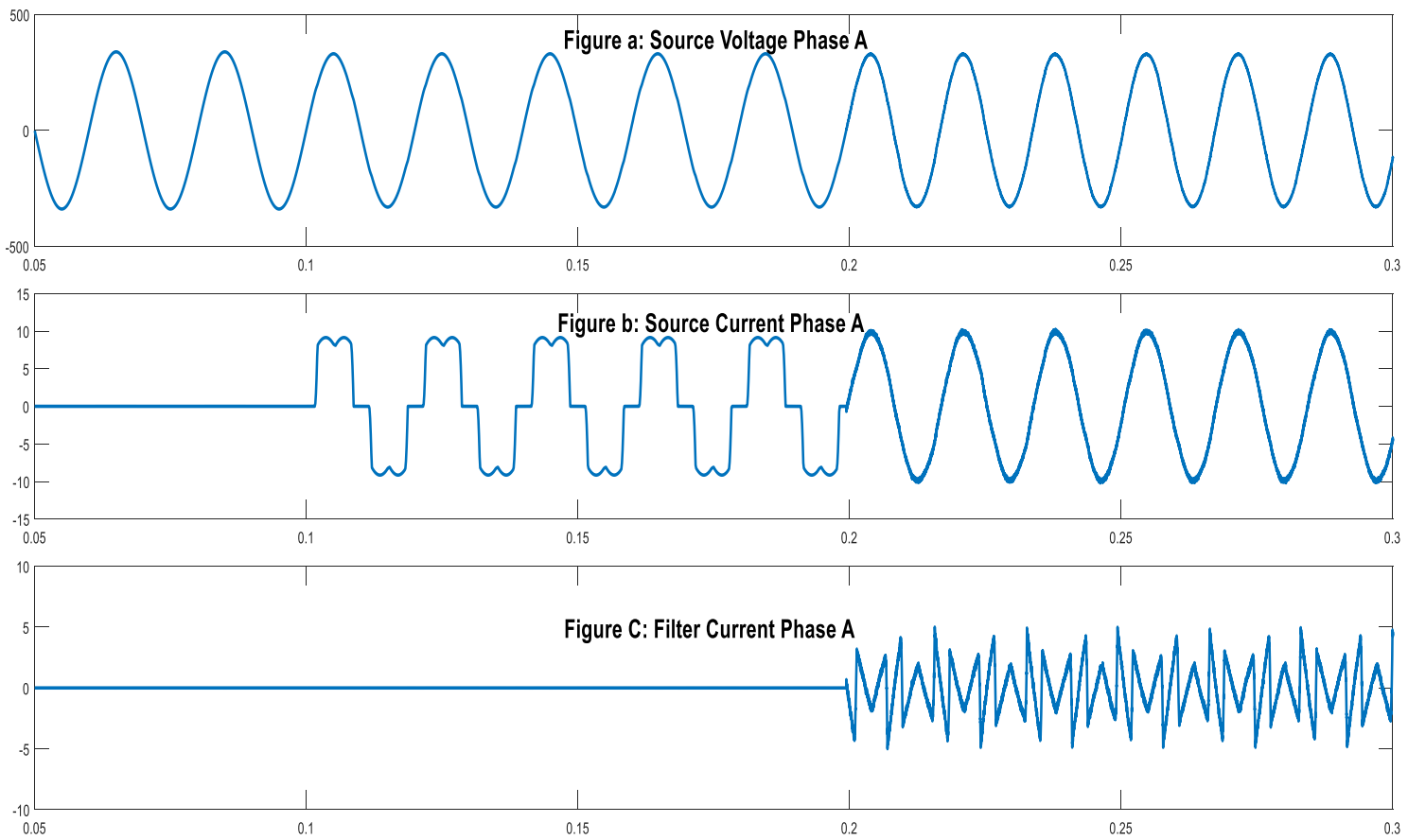

Figure 8. Phase A DCC waveform, (a) Source voltage, (b) Source current, and (c) Filter current

\subsection{Total harmonic compensation}

Both ICC and DCC modes perform as expected in controlling the harmonics of the source current at PCC. Based on the initial condition of the system without the APF, the harmonics measured is around $27.97 \%$, and when APF is applied, the harmonics are reduced to $2.01 \%$ and $2.43 \%$ for ICC and DCC respectively, as shown in Figure 9. The recorded total harmonic distortion (THDs) for all phases before and after mitigation are shown in Table 2. Based on this result, it is shown that APF with ICC is having better performance in mitigating harmonics compared to DCC. However, both are still ensuring APF to operate within the limit IEEE standard, which is below 5\%.

Table 2. THD's measured for ICC and DCC

\begin{tabular}{ccccc}
\hline \multirow{2}{*}{ PHASE } & \multicolumn{2}{c}{ ICC } & \multicolumn{2}{c}{ DCC } \\
\cline { 2 - 5 } & Without APF & With APF & Without APF & With APF \\
\hline PHASE A & $27.97 \%$ & $2.01 \%$ & $27.97 \%$ & $2.43 \%$ \\
PHASE B & $27.97 \%$ & $1.99 \%$ & $27.97 \%$ & $2.44 \%$ \\
PHASE C & $27.97 \%$ & $2.01 \%$ & $27.97 \%$ & $2.46 \%$ \\
\hline
\end{tabular}

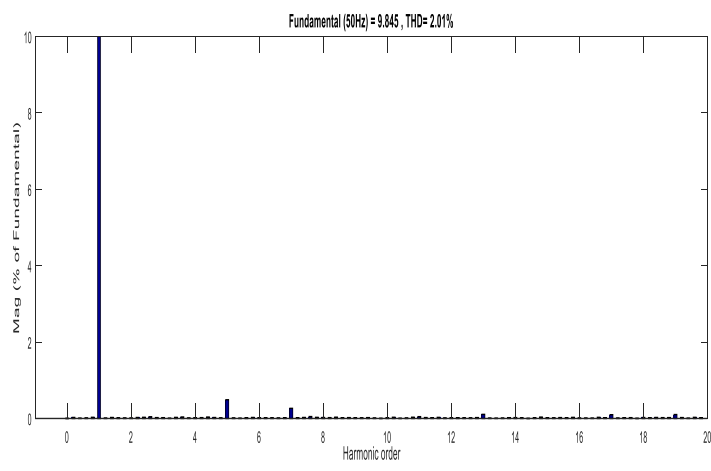

(a)

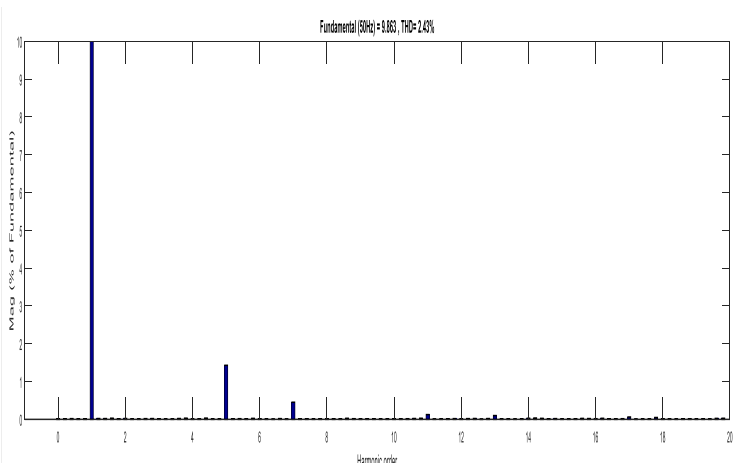

(b)

Figure 9. THD of phase A for, (a) ICC method, (b) DCC method 


\section{CONCLUSION}

In conclusion, ANF has been used in the shunt APF as harmonics extraction method for two current control methods. The work as demonstrated in the simulation is capable of extracting both fundamental and harmonics signals. When the ANF is simulated in DCC and ICC methods, the APF can mitigate the harmonics. Comparing both methods, as shown by the THD values, the ICC method is more capable on mitigating harmonics compared to the DCC method. However, in consideration as extraction method for $\mathrm{APF}$, the ANF is functioning perfectly as the extraction method.

\section{ACKNOWLEDGEMENTS}

The authors would like to express their sincere gratitude to the Ministry of Education Malaysia, UPM, ALPER UPM and UTeM for the technical and financial support of this research. The research was funded by Universiti Putra Malaysia under PUTRA Grant (9656100).

\section{REFERENCES}

[1] R. L. de Araujo Ribeiro, C. C. de Azevedo and R. M. de Sousa, "A Robust Adaptive Control Strategy of Active Power Filters for Power-Factor Correction, Harmonic Compensation, and Balancing of Nonlinear Loads," in IEEE Transactions on Power Electronics, vol. 27, no. 2, pp. 718-730, Feb. 2012.

[2] J. M. Maza-Ortega, J. A. Rosendo-Macias, A. Gómez-Expósito, S. Ceballos-Mannozzi and M. Barrágan-Villarejo, "Reference Current Computation for Active Power Filters by Running DFT Techniques," in IEEE Transactions on Power Delivery, vol. 25, no. 3, pp. 1986-1995, July 2010.

[3] H. Chen, H. Liu, Y. Xing, and H. Hu, "Enhanced DFT-based controller for selective harmonic compensation in active power filters," IEEE Transactions on Power Electronics., vol. 34, no. 8, pp. 8017-8030, August 2019.

[4] N. Elhaj, M. B. Sedra, and H. Djeghloud, "DFPI-based control of the DC-bus voltage and the AC-side current of a shunt active power filter," Bulletin of Electrical Engineering and Informatics, vol. 5, no. 4, pp. 430-441, 2016.

[5] A. Rahnamaei and M. Salimi, "A novel grid connected photovoltaic system," Bulletin of Electrical Engineering and Informatics, vol. 5, no. 2, pp. 133-143, 2016.

[6] R. Panigrahi and B. Subudhi, "Performance enhancement of shunt active power filter using a kalman filter-based Ho control strategy," IEEE Transactions on Power Electronics, vol. 32, no. 4, pp. 2622-2630, 2017.

[7] J. M. Kanieski, R. Cardoso, H. Pinheiro, and H. A. Gründling, "Kalman filter-based control system for power quality conditioning devices," IEEE Transactions on Industrial Electronics, vol. 60, no. 11, pp. 5214-5227, 2013.

[8] X. Nie and J. Liu, "Current reference control for shunt active power filters under unbalanced and distorted supply voltage conditions," IEEE Access, vol. 7, pp. 177048-177055, 2019.

[9] S. K. Jain and S. N. Singh, "Fast harmonic estimation of stationary and time-varying signals using EA-AWNN," IEEE Transactions on Instrumentation and Measurement, vol. 62, no. 2, pp. 335-343, 2013.

[10] C. V. Suru, C. A. Patrascu, and M. Linca, "The synchronous fundamental dq frame theory implementation and adaptation for the active filtering," 2014 International Conference on Applied and Theoretical Electricity (ICATE), pp. 1-6, 2014.

[11] A. A. A. Elgammal and M. F. El-naggar, "MOPSO-based optimal control of shunt active power filter using a variable structure fuzzy logic sliding mode controller for hybrid (FC-PV-Wind-Battery) energy utilisation scheme," IET Renewable Power Generation, vol. 11, no. 8, pp. 1148-1156, 2862017.

[12] Y. Hoon, M. A. Mohd Radzi, M. K. Hassan, and N. F. Mailah, "Enhanced instantaneous power theory with average algorithm for indirect current controlled three-level inverter-based shunt active power filter under dynamic state conditions," Mathematical Problems in Engineering, vol. 2016, pp. 1-12, 2016.

[13] Madhu B. R., Dinesh M. N., Ravitheja B. M., "Design of shunt hybrid active power filter (SHAPF) to reduce harmonics in AC side due to Non-linear loads," International Journal of Power Electronics and Drive System (IJPEDS), vol. 9, no. 4, pp. 1926-1936, 2018.

[14] S. Rahmani, N. Mendalek, and K. Al-Haddad, "Experimental design of a nonlinear control technique for threephase shunt active power filter," IEEE Transactions on Industrial Electronics, vol. 57, no. 10, pp. 3364-3375, Oct 2010.

[15] R. L. d. A. Ribeiro, T. d. O. A. Rocha, R. M. de Sousa, E. C. dos Santos and A. M. N. Lima, "A Robust DC-Link Voltage Control Strategy to Enhance the Performance of Shunt Active Power Filters Without Harmonic Detection Schemes," in IEEE Transactions on Industrial Electronics, vol. 62, no. 2, pp. 803-813, Feb. 2015

[16] M. Tamilvani, K. Nithya, M. Srinivasan, and S. Prabha, "Harmonic reduction in variable frequency drives using active power filter," Bulletin of Electrical Engineering and Informatics, vol. 3, no. 2, pp. 119-126, June 2014.

[17] A. Sabo, N. I. Abdulwahab, M. A. M. Radzi, N. F. Mailah and N. F. A. A. Rahman, "A modified digital hysteresis and artificial neural network (ANN) algorithms in single phase shunt active power filter control," 2014 IEEE Innovative Smart Grid Technologies-Asia (ISGT ASIA), Kuala Lumpur, pp. 198-203, 2014.

[18] Y. Hoon, M. A. M. Radzi, M. K. Hassan, and N. F. Mailah, "A self-tuning filter-based adaptive linear neuron approach for operation of three-level inverter-based shunt active power filters under non-ideal source voltage conditions," Energies, vol. 10, no. 5, 2017.

[19] M. A. A. Mohd Zainuri, M. A. M. Radzi, A. Che Soh, N. Mariun, and N. Abd Rahim, "Simplified adaptive linear neuron harmonics extraction algorithm for dynamic performance of shunt active power filter," International Review on Modelling and Simulations, vol. 9, no. 3, pp. 144-154, 2016. 
[20] Muhammad Ammirrul Atiqi Mohd Zainuri, Mohd Amran Mohd Radzi, Azura Che Soh, Norman Mariun, Nasrudin Abd Rahim, Shahrooz Hajighorbani, "Fundamental active current adaptive linear neural networks for photovoltaic shunt active power filters," Energies, vol. 9, no. 6, pp. 397, 2016.

[21] M. A. A. Mohd Zainuri, M. A. M. Radzi, A. Che Soh, N. Mariun, and N. Abd Rahim, "Improved ADALINE harmonics extraction algorithm for boosting performance of photovoltaic shunt active power filter under dynamic operations," Journal of Electrical Engineering and Technology, vol. 11, no. 6, pp. 1714-1728, 2016.

[22] P. A. Regalia, “A complex adaptive notch filter," IEEE Signal Processing Letters, vol. 17, no. 11, pp. 937-940, Nov. 2010.

[23] M. Mojiri, M. Karimi-ghartemani, and A. Bakhshai, "Time-domain signal analysis using adaptive notch filter," IEEE Transactions on Signal Processing., vol. 55, no. 1, pp. 85-93, Jan. 2007.

[24] M. Mojiri and A. R. Bakhshai, "Stability analysis of periodic orbit of an adaptive notch filter for frequency estimation of a periodic signal," Automatica, vol. 43, no. 3, pp. 450-455, March 2007.

[25] B. Singh, K. Kant and S. R. Arya, "Notch filter-based fundamental frequency component extraction to control distribution static compensator for mitigating current-related power quality problems," IET Power Electronics, vol. 8, no. 9, pp. 1758-1766, 2015.

[26] M. Karimi-Ghartemani, A. R. Bakhshai and M. Mojiri, "Estimation of Power System Frequency Using Adaptive Notch Filter," 2005 IEEE Instrumentationand Measurement Technology Conference Proceedings, Ottawa, Ont., pp. 1494-1497, 2005.

[27] D. Yazdani, A. Bakhshai, and P. K. Jain, "A three-phase adaptive notch filter-based approach to harmonic/reactive current extraction and harmonic decomposition," IEEE Transactions on Power Electronics, vol. 25, no. 4, pp. 914-923, Apr. 2010.

[28] S. H. Tabatabaei, M. Moslehi Bajestan, and A. Jalilian, "Shunt active power filter control for compensating current power quality problems in three-phase three-wire systems based on an adaptive notch filter," Turkish Journal of Electrical Engineering \& Computer Sciences, vol. 24, no. 4, pp. 2539-2555, 2016.

[29] N. D. Tuyen, G. Fujita, T. Funabashi, and M. Nomura, "Adaptive notch filter for synchronization and islanding detection using negative-sequence impedance measurement," IEEJ Transactions on Electrical and Electronic Engineering, vol. 7, no. 3, pp. 240-250, May 2012. 